\title{
ANALYSIS OF FORCED VIBRATIONS OF NONLINEAR PLATES IN A VISCOELASTIC MEDIUM UNDER THE CONDITIONS OF THE DIFFERENT COMBINATIONAL INTERNAL RESONANCES
}

\author{
Marina V. Shitikova, Vladimir V. Kandu \\ Voronezh State Technical University, Voronezh, RUSSIA
}

\begin{abstract}
In the present paper, the force driven dynamic response of a nonlinear plate embedded in a viscoelastic medium, damping features of which are described by the Kelvin-Voigt fractional derivative model, is studied. The motion of the plate is described by three coupled nonlinear differential equations with due account for the fact that the plate is being under the conditions of the internal combinational resonance accompanied by the external resonance, resulting in the interaction of three modes corresponding to the mutually orthogonal displacements. A comparative analysis of numerical calculations for the cases of free and forced vibrations has been carried out.
\end{abstract}

Keywords: Nonlinear vibrations of thin plates, interaction of internal and external resonances, fractional derivative viscoelastic surrounding medium, combinational internal resonance

\section{ЧИСЛЕННЫЙ АНАЛИЗ ВЫНУЖДЕННЫХ НЕЛИНЕЙНЫХ КОЛЕБАНИЙ ПЛАСТИНОК В ВЯЗКОУПРУГОЙ СРЕДЕ ПРИ НАЛИЧИИ КОМБИНАЦИОННОГО РЕЗОНАНСА}

\author{
М.В. Шитикова, В.В. Канду \\ Воронежский государственный технический университет, г. Воронеж, РОССИЯ
}

\begin{abstract}
Аннотация: Исследованы нелинейные вынужденные колебания тонких пластинок в вязкоупругой среде, демпфирующие свойства которой задаются с помощью модели Кельвина-Фойгта с дробной производной. Колебания пластинки в вязкоупругой среде описываются в декартовской системе координат тремя дифференциальными уравнениями, с учетом того, что пластинка находится в условиях внутреннего комбинационного резонанса, сопровождаемого внешним резонансом. Приведен сравнительный анализ численных исследований свободных и вынужденных колебаний при наличии различных комбинационных внутренних резонансов для различных геометрических параметров пластинки.
\end{abstract}

Ключевые слова: нелинейные колебания пластинок, сочетание внутреннего и внешнего резонансов, дробная производная, комбинационный резонанс

\section{INTRODUCTION}

Recently the interest to nonlinear dynamic response of viscoelastic plates or elastic plates vibrating in a viscoelastic surrounding medium has been greatly renewed due to the appearance of advanced materials exhibiting nonlinear behaviour, and a comprehensive review in the field, including experimental results, could be found in [1-6]. In so doing the damping forces are usually taken into account via the Rayleigh's hypothesis [1,7], resulting in the modal damping [8], i.e. it is assumed that each natural mode of vibrations possesses its own damping coefficient dependent on its natural frequency. For describing the viscoelastic features of plates, the Kelvin-Voigt model [4] or standard linear solid model [5] are of 
frequent use in engineering practice considering either linear or nonlinear springs in viscoelastic elements [9].

The analysis of free undamped [10] and damped [4] vibrations of nonlinear systems is of great importance for defining the dynamic system's characteristics dependent on the amplitudephase relationships and modes of vibration. Moreover, nonlinear vibrations could be accompanied by such a phenomenon as the internal resonance, resulting in strong coupling between the modes of vibrations involved [1015] and hence in the energy exchange between the interacting modes.

The internal resonance could be observed in the case of some combination of natural frequencies of one and the same type of vibrations. Thus, nonlinear vibrations of rectangular plates, dynamic behaviour of which is described by von Karman equations in terms of the plate's deflection and stress function, have been considered in [12] by reducing the governing equations to a set of two modal equations applying the Galerkin procedure. The case of the one-to-one internal resonance (when frequencies of two modes of flexural vibration are equal to each other) accompanied by the external resonance (when the frequency of the harmonic force is close to one of the natural frequency) has been studied.

The one-to-one internal resonance has been investigated also in [13] and [14] for nonlinear vertical vibrations of rectangular plates under the action of harmonic forces acting in the plate's plane [13] and out of the plate's plane $[13,14]$, in so doing a set of three equations in terms of two in-plane displacements and deflection and a set of five equations considering the shear deformations have been used in [13] and [14], respectively. However, considering the inertia forces only for vertical vibrations and utilizing the Galerkin procedure, in both papers a set of two nonlinear equations has been obtained in terms of two flexural modes, which are assumed to be coupled via the one-to-one internal resonance.
For the first two natural modes of flexural vibrations, the cases of the 1:2 and 1:3 internal resonances have been also studied in [14].

Another type of the internal resonance has been investigated by Rossikhin and Shitikova [1518], when one frequency of in-plane vibrations is equal (the 1:1 internal resonance $[17,18]$ ) or two times larger (the 1:2 internal resonance $[15,18])$ than a certain frequency of out-of-plane vibrations. As this takes place, a set of three nonlinear differential equations in terms of three mutually orthogonal displacements has been used considering inertia of all types of vibrations, what allows the authors to study further the combinational resonances of the additive and difference types [16,19-20]. Combinational types of the internal resonance result in the energy exchange between three or more subsystems. It should be noted that investigations in this direction were initiated by Witt and Gorelik [21], who pioneered in the theoretical and experimental analysis of the energy transfer from one subsystem to another using the simplest two-degree-of-freedom mechanical system, as an example.

Moreover, in order to study nonlinear free damped vibrations of a thin plate, the viscoelastic Kelvin-Voigt model involving fractional derivative [22] has been utilized, since this model possesses the advantage over the conventional Kelvin-Voigt model [10-14], because it provides the results matching the experimental data. Thus, for example, experimental data on ambient vibrations study for the Vincent-Thomas [23] and Golden Gate [24] suspension bridges have shown that different modes of vibrations possess different magnitudes of damping coefficients. Besides, the increase in the natural frequency results in the decrease in the damping ratio. In order to lead the theoretical investigation in the agreement with the experiment, in 1998 it was suggested in [25] to utilize the fractional derivatives to describe the processes of internal friction occurring in suspension combined systems, what allowed the authors in a natural 
way to obtain the damping ratios, which depend on natural frequencies.

Nowadays fractional calculus is widely used for solving linear and nonlinear dynamic problems of structural mechanics, what is evident from numerous studies in the field, the overview of which could be found in the state-of-the-art articles by Rossikhin and Shitikova [26,27], wherein the examples of adopting the fractional derivative Kelvin-Voigt, Maxwell and standard linear solid models are provided for single-mass oscillators, rods, beams, plates, and shells.

In particular, linear vibrations of KirchhoffLove plates with the Kelvin-Voigt fractional damping were considered for rectangular and circular plates, respectively, in [28] and [29] using one equation for vertical vibrations, while utilizing three equations of in-plane and transverse vibrations in [7,30], and later multiplate systems were analyzed in [26,31]. It has been proved [27,32] that if viscoelastic properties of plates are described by the KelvinVoigt model assuming the Poisson's ratio as the time-independent value (though for real viscoelastic materials the Poisson's ratio is always a time-dependent function [33]), then this case coincides with the case of the dynamic behaviour of elastic bodies in a viscoelastic medium. Thus, the authors of [28,29], and not only them, replaced one problem with another, namely: a problem of the dynamic response of viscoelastic Kirchhoff-Love plates in a conventional medium with a problem of dynamic response of elastic Kirchhoff-Love plates in a viscoelastic medium, damping features of which are governed by the fractional derivative Kelvin-Voigt model. The vibration suppression of fractionally damped thin rectangular simply supported plates subjected to a concentrated harmonic loading has been studied recently in [34] in order to minimize the plate deflection, in so doing the vibration suppression is accomplished by attaching multiple absorbers modelled as the KelvinVoigt fractional oscillators, i.e. generalizing the approach suggested in [26,31].
As for the analysis of nonlinear vibrations of plates, then except the above mentioned papers [15-20], the fractional derivative Kelvin-Voigt model was used in [35-40] and fractional derivative standard linear solid model in $[6,41,42]$ but without considering the phenomena of the internal resonance. Thus, free and forced vertical vibrations of an orthotropic plate have been studied in [35] considering first four modes of flexural vibrations, and during the analysis of force driven vibrations the frequency of a harmonic force was assumed to be equal to one of natural frequencies. The von Karman plate equation with fractional derivative damping was utilized in [36] for analyzing the cases of primary, subharmonic and superharmonic resonance conditions, when the harmonic force frequency, respectively, is approximately equal, three times less or larger than the first or second natural frequency of vertical vibrations. Nonlinear random vibrations of the same plate was studied in [39]. Dynamic nonlinear response to random excitation of a simply supported rectangular plate based on a foundation, damping features of which are described by the fractional derivative KelvinVoigt model, has been considered in [38]. The analysis of chaotic vibrations of simply supported nonlinear viscoelastic plate with fractional derivative Kelvin-Voigt model has been carried out in [40] for the case when the plate is subjected to an in-plane harmonic force in one direction and a transverse harmonic force. The Galerkin decomposition has been used to obtain the modal equation of the system, in so doing the authors restricted themselves only by the first mode. The fractional derivative standard linear solid model has been utilized in [42] for a viscoelastic layer for active damping of geometrically nonlinear vibrations of smart composite plates using the higher order plate theory and finite element method with discretizing the plate by eight-node isoparametric quadrilateral elements.

In the present paper, the approaches suggested in [18] for solving the problem on free nonlinear vibrations of elastic plates in a viscoelastic 
medium, damping features of which are governed by the Riemann-Liouville derivatives of the fractional order, and in [43] for studying the dynamic response of the fractional Duffing oscillator subjected to harmonic loading are generalized for the case of forced vibrations of a simply-supported nonlinear thin elastic plate under the conditions of different combinational internal resonances, when three natural modes corresponding to mutually orthogonal displacements are coupled.

\section{PROBLEM FORMULATION}

\subsection{Governing equations.}

Let us consider the dynamic behavior of a simply supported nonlinear thin rectangular plate, vibrations of which in a viscoelastic fractional derivative medium are described by the following three differential equations in the dimensionless form $[44,45]$ :

$$
\begin{aligned}
& u_{x x}+\frac{1-v}{2} \beta_{1}^{2} u_{y y}+\frac{1+v}{2} \beta_{1} v_{x y}+\frac{1+v}{2} \beta_{1}^{2} w_{y} w_{x y}+ \\
& +w_{x}\left(w_{x x}+\frac{1-v}{2} \beta_{1}^{2} w_{y y}\right)=\ddot{u}+\mathfrak{x}_{1} D_{0+}^{\gamma} u, \\
& \beta_{1}^{2} v_{y y}+\frac{1-v}{2} v_{x x}+\frac{1+v}{2} \beta_{1} u_{x y}+\frac{1+v}{2} \beta_{1} w_{x} w_{x y}+ \\
& +\beta_{1} w_{y}\left(\beta_{1}^{2} w_{y}+\frac{1-v}{2} w_{x x}\right)=\ddot{v}+\mathfrak{x}_{2} D_{0+}^{\gamma} v, \\
& \frac{\beta_{2}^{2}}{12}\left(w_{x x x x}+2 \beta_{1}^{2} w_{x x y y}+\beta_{1}^{4} w_{y y y y}\right)- \\
& -w_{x x}\left(u_{x}+v \beta_{1} v_{y}\right)-w_{x}\left(u_{x x}+v \beta_{1} v_{x y}\right)- \\
& -\frac{1-v}{2} \beta_{1}\left[w_{x y}\left(\beta_{1} u_{y}+v_{x}\right)+w_{y}\left(\beta_{1} u_{x y}+v_{x x}\right)\right]- \\
& -\beta_{1}^{2}\left[w_{y y}\left(v u_{x}+\beta_{1} v_{y}\right)+w_{y}\left(v u_{x y}+\beta_{1} v_{y y}\right)\right]- \\
& -\frac{1-v}{2} \beta_{1}\left[w_{x y}\left(\beta_{1} u_{y}+v_{x}\right)+w_{x}\left(\beta_{1} u_{y y}+v_{x y}\right)\right]- \\
& -\hat{F} \delta\left(x-x_{0}\right) \delta\left(y-y_{0}\right) \cos \left(\Omega_{F} t\right)= \\
& =-\ddot{w}-\mathfrak{X}_{3} D_{0+}^{\gamma} w,
\end{aligned}
$$

where $\quad u=u(x, y, t), \quad v=v(x, y, t), \quad$ and $w=w(x, y, t)$ are the displacements of points located in the plate's middle surface in the $x$-, $y$-, and $z$-directions, respectively, $v$ is the Poisson's ratio, $\beta_{1}=a / b$ and $\beta_{2}=h / a$ are the parameters defining the dimensions of the plate, $a$ and $b$ are the plate's dimensions along the $x$ and $y$-axes, respectively, $h$ is the thickness, $t$ is the time,

$$
F=\hat{F} \delta\left(x-x_{0}\right) \delta\left(y-y_{0}\right) \cos \left(\Omega_{F} t\right)
$$

is the harmonic force applied at the point with the coordinates $x_{0}, y_{0}, \hat{F}$ and $\Omega_{F}$ are its amplitude and frequency, respectively, $\delta$ is the Dirac delta function,

$$
\mathfrak{x}_{i}=\varepsilon \mu_{i} \tau_{i}^{\gamma}(i=1,2,3)
$$

are damping coefficients, $\varepsilon$ is a small dimensionless parameter of the same order of magnitude as the amplitudes, $\mu_{i}$ are finite values, $\tau_{i}$ is the relaxation time of the $i$ th generalized displacement, $D_{0+}^{\gamma}$ is the RiemannLiouville fractional derivative of the $\gamma$-order [46], an overdot denotes the time-derivative, and lower indices label the derivatives with respect to the corresponding coordinates.

For solving nonlinear governing equations of motion (1)-(3), the procedure resulting in decoupling linear parts of equations has been proposed with the further utilization of the method of multiple scales $[18,44,45]$, in so doing the amplitude functions are expanded into power series in terms of the small parameter and depend on different time scales. It has been shown that the phenomenon of internal resonance could be very critical, since in the thin plate under consideration the internal resonance is always present. Moreover, its type depends on the order of smallness of the viscosity involved into consideration [18]. The 
following types of the internal resonance have been revealed:

of the order of $\varepsilon$ :

the two-to-one internal resonance $(1: 2)$

$$
\begin{array}{ll}
\omega_{1}=2 \omega_{3} & \left(\omega_{2} \neq \omega_{1}, \omega_{2} \neq 2 \omega_{3}\right), \\
\omega_{2}=2 \omega_{3} & \left(\omega_{1} \neq \omega_{2}, \omega_{1} \neq 2 \omega_{3}\right) ;
\end{array}
$$

the one-to-one-to-two internal resonance

$$
(1: 1: 2)
$$

$\omega_{1}=\omega_{2}=2 \omega_{3}$

of the order of $\varepsilon^{2}$ :

the one-to-one internal resonance $(1: 1)$

$$
\begin{array}{ll}
\omega_{1}=\omega_{2} & \left(\omega_{3} \neq \omega_{1}, \omega_{3} \neq \omega_{2}\right), \\
\omega_{1}=\omega_{3} & \left(\omega_{2} \neq \omega_{1}, \omega_{2} \neq \omega_{3}\right), \\
\omega_{2}=\omega_{3} & \left(\omega_{1} \neq \omega_{2}, \omega_{1} \neq \omega_{3}\right) ;
\end{array}
$$

the one-to-one-to-one internal resonance $(1: 1: 1)$

$$
\omega_{1}=\omega_{2}=\omega_{3}
$$

the combinational resonance of the additivedifference type

$$
\begin{aligned}
& 2 \omega_{3}=\omega_{1}+\omega_{2}, \\
& 2 \omega_{3}=\omega_{1}-\omega_{2}, \\
& 2 \omega_{3}=\omega_{2}-\omega_{1},
\end{aligned}
$$

where $\omega_{1}$ and $\omega_{2}$ are the frequencies of certain modes of in-plane vibrations in the $x$ - and $y$ axes, respectively, and $\omega_{3}$ is the frequency of a certain mode of vertical vibrations.

Note that the cases of the internal resonances (4)-(7) have been studied recently by the authors in $[44,45,47,48]$. Thus, below we will examine in detail all possible cases of the combinational resonances (8)-(10).

\subsection{Combinational resonance of the additive type $2 \omega_{3} \simeq \omega_{1}+\omega_{2}$}

Now let us consider the case of the additive internal combinational resonance accompanied by the external resonance, i.e.,

$$
2 \omega_{3}=\omega_{1}+\omega_{2}+2 \varepsilon^{2} \sigma
$$

and

$$
\Omega_{F}=\omega_{3}+\varepsilon^{2} \sigma_{F},
$$

where $\sigma$ is the detuning parameter characterizing the nearness between the natural frequencies of the coupled modes, and $\sigma_{F}$ is the second detuning parameter defining the difference between the frequency of vertical vibrations and the frequency of the external force $\Omega_{F}$.

Using the set of solvability equations to eliminate secular terms similarly to the case of free vibrations considered in [18] and adding the external resonance, we obtain the following solvability equations for the case of force driven vibrations:

$2 i \omega_{1} D_{2} A_{1}+\mu_{1}\left(i \omega_{1} \tau_{1}\right)^{\gamma} A_{1}+2 \zeta_{1}\left(k_{5}+k_{7}\right) A_{1} A_{3} \bar{A}_{3}+$ $+2 \zeta_{1} k_{8} \bar{A}_{2} A_{3}^{2} \exp \left(2 i \sigma T_{2}\right)=0$,

$2 i \omega_{2} D_{2} A_{2}+\mu_{2}\left(i \omega_{2} \tau_{2}\right)^{\gamma} A_{2}+2 \zeta_{2}\left(k_{6}+k_{8}\right) A_{2} A_{3} \bar{A}_{3}+$ $+2 \zeta_{2} k_{7} \bar{A}_{1} A_{3}^{2} \exp \left(2 i \sigma T_{2}\right)=0$,

$2 i \omega_{3} D_{2} A_{3}+\mu_{3}\left(i \omega_{3} \tau_{3}\right)^{\gamma} A_{3}+$

$+\left[\zeta_{13}\left(k_{1}+2 k_{2}\right)+\zeta_{23}\left(k_{3}+2 k_{4}\right)\right] A_{3}^{2} \bar{A}_{3}+$

$+\zeta_{13}\left(k_{5}+k_{7}\right) A_{1} \bar{A}_{1} A_{3}+\zeta_{23}\left(k_{6}+k_{8}\right) A_{2} \bar{A}_{2} A_{3}+(14)$

$+\left(\zeta_{13} k_{8}+\zeta_{23} k_{7}\right) A_{1} A_{2} \bar{A}_{3} \exp \left(-2 i \sigma T_{2}\right)-$

$-2 f \exp \left(i \sigma_{F} T_{2}\right)=0$,

where $D_{2}=\partial / \partial T_{2}$ is the time-derivative due to the utilization of the generalized method of 
multiple time scales [18], $A_{j}\left(T_{2}\right)(j=1,2,3)$ are unknown complex functions, $\zeta_{1}, \zeta_{2}, \zeta_{13}, \zeta_{23}$ are coefficients depending on the plate dimensions and numbers of excited modes [18], $k_{p}(p=1,2, \ldots 8)$ are coefficients depending on the natural frequencies of plate, and $t$ is a finite value.

To eliminate $\exp \left( \pm 2 i \sigma_{1} T_{2}\right)$ from equations (11)-(13), let us introduce the substitution

$$
A_{3}\left(T_{2}\right)=A_{3} \exp \left(-i \sigma T_{2}\right) .
$$

Representing the functions $A_{i}\left(T_{2}\right)$ in equations (11)-(13) in the polar form

$$
A_{i}\left(T_{2}\right)=a_{i}\left(T_{2}\right) \exp \left\lfloor i \varphi_{i}\left(T_{2}\right)\right\rfloor(i=1,2,3)
$$

and separating real and imaginary parts yield

$$
\begin{aligned}
& \left(a_{1}^{2}\right)^{-}+s_{1} a_{1}^{2}=-2 \omega_{1}^{-1} \zeta_{1} k_{8} a_{1} a_{2} a_{3}^{2} \sin \delta \\
& \left(a_{2}^{2}\right)^{-}+s_{2} a_{2}^{2}=-2 \omega_{2}^{-1} \zeta_{2} k_{7} a_{1} a_{2} a_{3}^{2} \sin \delta \\
& \left(a_{3}^{2}\right)^{+}+s_{3} a_{3}^{2}=-2 f \omega_{3}^{-1} a_{3} \sin \beta_{a}+ \\
& +\omega_{3}^{-1}\left(\zeta_{13} k_{8}+\zeta_{23} k_{7}\right) a_{1} a_{2} a_{3}^{2} \sin \delta \\
& \dot{\varphi}_{1}-\frac{1}{2} \lambda_{1}+\omega_{1}^{-1} \zeta_{1}\left(k_{5}+k_{7}\right) a_{3}^{2}+ \\
& \quad+\omega_{1}^{-1} \zeta_{1} k_{8} a_{1}^{-1} a_{2} a_{3}^{2} \cos \delta \\
& \dot{\varphi}_{2}-\frac{1}{2} \lambda_{2}+\omega_{2}^{-1} \zeta_{2}\left(k_{6}+k_{8}\right) a_{3}^{2}+ \\
& +\omega_{2}^{-1} \zeta_{2} k_{7} a_{1} a_{2}^{-1} a_{3}^{2} \cos \delta \\
& \dot{\varphi}_{3}-\frac{1}{2} \lambda_{3}+\frac{1}{2} \omega_{3}^{-1} \zeta_{13}\left(k_{5}+k_{7}\right) a_{1}^{2}+ \\
& +\frac{1}{2} \omega_{3}^{-1} \zeta_{23}\left(k_{6}+k_{8}\right) a_{2}^{2}+ \\
& +\frac{1}{2} \omega_{3}^{-1}\left[\zeta_{13}\left(k_{1}+2 k_{2}\right)+\zeta_{23}\left(k_{3}+2 k_{4}\right)\right] a_{3}^{2}+(21) \\
& +\frac{1}{2} \omega_{3}^{-1}\left(\zeta_{13} k_{8}+\zeta_{23} k_{7}\right) a_{1} a_{2} \cos \delta- \\
& -f\left(\omega_{3} a_{3}\right)^{-1} \cos \beta_{a}+\sigma,
\end{aligned}
$$

and

$$
\Omega_{F}=\omega_{3}+\varepsilon^{2} \sigma_{F} .
$$

Then eliminating secular terms, we obtain the following solvability equations:

$$
\begin{aligned}
& 2 i \omega_{1} D_{2} A_{1}+\mu_{1}\left(i \omega_{1} \tau_{1}\right)^{\gamma} A_{1}+2 \zeta_{1}\left(k_{5}+k_{7}\right) A_{1} A_{3} \bar{A}_{3}+ \\
& +2 \zeta_{1} k_{6} A_{2} A_{3}^{2} \exp \left(2 i \sigma T_{2}\right)=0,
\end{aligned}
$$$$
2 i \omega_{2} D_{2} A_{2}+\mu_{2}\left(i \omega_{2} \tau_{2}\right)^{\gamma} A_{2}+2 \zeta_{2}\left(k_{6}+k_{8}\right) A_{2} A_{3} \bar{A}_{3}+
$$$$
+2 \zeta_{2} k_{7} A_{1} \bar{A}_{3}^{2} \exp \left(-2 i \sigma T_{2}\right)=0 \text {, }
$$ 
Analysis of Forced Vibrations of Nonlinear Plates in a Viscoelastic Medium Under the Conditions of the Different Combinational Internal Resonances

$$
\begin{aligned}
& 2 i \omega_{3} D_{2} A_{3}+\mu_{3}\left(i \omega_{3} \tau_{3}\right)^{\gamma} A_{3}+ \\
& {\left[\zeta_{13}\left(k_{1}+2 k_{2}\right)+\zeta_{23}\left(k_{3}+2 k_{4}\right)\right] A_{3}^{2} \bar{A}_{3}+} \\
& +\zeta_{13}\left(k_{5}+k_{7}\right) A_{1} \bar{A}_{1} A_{3}+\zeta_{23}\left(k_{6}+k_{8}\right) A_{2} \bar{A}_{2} A_{3}+(24) \\
& +\left(\zeta_{13} k_{6}+\zeta_{23} k_{7}\right) A_{1} \bar{A}_{2} \bar{A}_{3} \exp \left(-2 i \sigma T_{2}\right)- \\
& -2 f \exp \left(i \sigma_{F} T_{2}\right)=0 .
\end{aligned}
$$

Applying to (21)-(23) the same procedure as it has been done above for (11)-(13), as a result, we have

$$
\begin{aligned}
& \left(a_{1}^{2}\right)^{+}+s_{1} a_{1}^{2}=-2 \omega_{1}^{-1} \zeta_{1} k_{6} a_{1} a_{2} a_{3}^{2} \sin \delta, \\
& \left(a_{2}^{2}\right)+s_{2} a_{2}^{2}=2 \omega_{2}^{-1} \zeta_{2} k_{7} a_{1} a_{2} a_{3}^{2} \sin \delta, \\
& \left(a_{3}^{2}\right)+s_{3} a_{3}^{2}=-2 f \omega_{3}^{-1} a_{3} \sin \beta_{a}+ \\
& +\omega_{3}^{-1}\left(\zeta_{13} k_{6}+\zeta_{23} k_{7}\right) a_{1} a_{2} a_{3}^{2} \sin \delta, \\
& \dot{\varphi}_{1}=\frac{1}{2} \lambda_{1}+\omega_{1}^{-1} \zeta_{1}\left(k_{5}+k_{7}\right) a_{3}^{2}+ \\
& +\omega_{1}^{-1} \zeta_{1} k_{6} a_{1}^{-1} a_{2} a_{3}^{2} \cos \delta, \\
& \dot{\varphi}_{2}-\frac{1}{2} \lambda_{2}+\omega_{2}^{-1} \zeta_{2}\left(k_{6}+k_{8}\right) a_{3}^{2}+ \\
& +\omega_{2}^{-1} \zeta_{2} k_{7} a_{1} a_{2}^{-1} a_{3}^{2} \cos \delta, \\
& \dot{\varphi}_{3}-\frac{1}{2} \lambda_{3}+\frac{1}{2} \omega_{3}^{-1} \zeta_{13}\left(k_{5}+k_{7}\right) a_{1}^{2}+ \\
& +\frac{1}{2} \omega_{3}^{-1} \zeta_{23}\left(k_{6}+k_{8}\right) a_{2}^{2}+\sigma_{1}+ \\
& +\frac{1}{2} \omega_{3}^{-1}\left[\zeta_{13}\left(k_{1}+2 k_{2}\right)+\zeta_{23}\left(k_{3}+2 k_{4}\right)\right] a_{3}^{2}+ \\
& +\frac{1}{2} \omega_{3}^{-1}\left(\zeta_{13} k_{6}+\zeta_{23} k_{7}\right) a_{1} a_{2} \cos \delta- \\
& -f\left(\omega_{3} a_{3}\right)^{-1} \cos \beta_{a},
\end{aligned}
$$$$
\text { where } \delta=2 \varphi_{3}+\varphi_{2}-\varphi_{1}
$$$$
\text { is the phase difference. }
$$

The set of Eqs. (24)-(29) describes the phaseamplitude modulations at nonlinear forced vibrations (1)-(3) in the case of the difference combinational resonance $(9)$.

\subsection{Combinational resonances of the difference type $2 \omega_{3} \simeq \omega_{2}-\omega_{1}$}

Now let us consider the difference combinational resonance (10) subjected to the external resonance, i.e. when

$$
2 \omega_{3}=\omega_{2}-\omega_{1}+2 \varepsilon^{2} \sigma
$$

and

$$
\Omega_{F}=\omega_{3}+\varepsilon^{2} \sigma_{F} .
$$

In this case the solvability equations have the form

$$
\begin{aligned}
& 2 i \omega_{1} D_{2} A_{1}+\mu_{1}\left(i \omega_{1} \tau_{1}\right)^{\gamma} A_{1}+2 \zeta_{1}\left(k_{5}+k_{7}\right) A_{1} A_{3} \bar{A}_{3}+ \\
& +2 \zeta_{1} k_{8} A_{2} \bar{A}_{3}^{2} \exp \left(-2 i \sigma T_{2}\right)=0 \\
& 2 i \omega_{2} D_{2} A_{2}+\mu_{2}\left(i \omega_{2} \tau_{2}\right)^{\gamma} A_{2}+2 \zeta_{2}\left(k_{6}+k_{8}\right) A_{2} A_{3} \bar{A}_{3}+ \\
& +2 \zeta_{2} k_{5} A_{1} A_{3}^{2} \exp \left(2 i \sigma T_{2}\right)=0,
\end{aligned}
$$

$2 i \omega_{3} D_{2} A_{3}+\mu_{3}\left(i \omega_{3} \tau_{3}\right)^{\gamma} A_{3}+$

$+\left[\zeta_{13}\left(k_{1}+2 k_{2}\right)+\zeta_{23}\left(k_{3}+2 k_{4}\right)\right] A_{3}^{2} \bar{A}_{3}+$

$+\zeta_{13}\left(k_{5}+k_{7}\right) A_{1} \bar{A}_{1} A_{3}+\zeta_{23}\left(k_{6}+k_{8}\right) A_{2} \bar{A}_{2} A_{3}+(33)$

$+\left(\zeta_{13} k_{8}+\zeta_{23} k_{5}\right) \bar{A}_{1} A_{2} \bar{A}_{3} \exp \left(-2 i \sigma T_{2}\right)-$

$-2 f \exp \left(i \sigma_{F} T_{2}\right)=0$.

Applying to (29)-(31) the same procedure as it has been done above for (11)-(13), as a result, we have

$\left(a_{1}^{2}\right)+s_{1} a_{1}^{2}=2 \omega_{1}^{-1} \zeta_{1} k_{8} a_{1} a_{2} a_{3}^{2} \sin \delta$,

$\left(a_{2}^{2}\right)^{j}+s_{2} a_{2}^{2}=-2 \omega_{2}^{-1} \zeta_{2} k_{5} a_{1} a_{2} a_{3}^{2} \sin \delta$,

$\left(a_{3}^{2}\right)+s_{3} a_{3}^{2}=-2 f \omega_{3}^{-1} a_{3} \sin \beta_{a}+$

$+\omega_{3}^{-1}\left(\zeta_{13} k_{8}+\zeta_{23} k_{5}\right) a_{1} a_{2} a_{3}^{2} \sin \delta$,

$\dot{\varphi}_{1}-\frac{1}{2} \sigma_{1}+\omega_{1}^{-1} \zeta_{1}\left(k_{5}+k_{7}\right) a_{3}^{2}+$

$+\omega_{1}^{-1} \zeta_{1} k_{8} a_{1}^{-1} a_{2} a_{3}^{2} \cos \delta$, 


$$
\begin{aligned}
& \dot{\varphi}_{2}-\frac{1}{2} \lambda_{2}+\omega_{2}^{-1} \zeta_{2}\left(k_{6}+k_{8}\right) a_{3}^{2}+ \\
& +\omega_{2}^{-1} \zeta_{2} k_{5} a_{1} a_{2}^{-1} a_{3}^{2} \cos \delta \\
& \dot{\varphi}_{3}-\frac{1}{2} \lambda_{3}+\frac{1}{2} \omega_{3}^{-1} \zeta_{13}\left(k_{5}+k_{7}\right) a_{1}^{2}+ \\
& +\frac{1}{2} \omega_{3}^{-1} \zeta_{23}\left(k_{6}+k_{8}\right) a_{2}^{2}+\sigma_{1}+ \\
& +\frac{1}{2} \omega_{3}^{-1}\left[\zeta_{13}\left(k_{1}+2 k_{2}\right)+\zeta_{23}\left(k_{3}+2 k_{4}\right)\right] a_{3}^{2}+(39) \\
& +\frac{1}{2} \omega_{3}^{-1}\left(\zeta_{13} k_{8}+\zeta_{23} k_{5}\right) a_{1} a_{2} \cos \delta- \\
& -f\left(\omega_{3} a_{3}\right)^{-1} \cos \beta_{a},
\end{aligned}
$$

where $\delta=2 \varphi_{3}+\varphi_{1}-\varphi_{2}$

is the phase difference.

The set of Eqs. (33)-(38) describes the phaseamplitude modulations at nonlinear forced vibrations (1)-(3) in the case of the difference combinational resonance (10).

\section{NUMERICAL CALCULATIONS}

The differential equations (15)-(20), (24)-(29) and (33)-(38) describing the phase-amplitude modulation for the additive and difference combinational resonances (8)-(10) have been solved numerically using the Runge-Kutta fourth-order algorithm at different magnitudes of the fractional parameter $\gamma$. The geometrical parameters of the plate utilized for calculations are given in Table 1 for three types of the combinational resonance for three types of plates: square, rectangular and oblong.

The envelopes of the amplitudes for all nine examples presented in Table 1 are shown in Figures 1-9 for free $(f=0)$ and forced $(f \neq 0)$ vibrations, wherein solid, dotted and dashed lines correspond to the functions $a_{3}\left(T_{2}\right), a_{2}\left(T_{2}\right)$ and $a_{1}\left(T_{2}\right)$, respectively, allowing one to trace the energy exchange between three interacting modes coupled by the additive-difference combinational resonances (8)-(10).

The time $T_{2}$-dependence of the amplitude envelopes for a rectangular plate with the dimensions $a=0.57 \mathrm{~m}$ and $b=0.1425 \mathrm{~m}$ (cases № 1, 4 and 7 in Table 1) are shown in Figures 1, 4 and 7 at $f=10$ for three types of the combinational resonance. It is seen that the most unfavorable is the difference combinational resonance

$$
2 \omega_{3} \simeq \omega_{2}-\omega_{1},
$$

Table 1. Plate parameters which satisfy the combinational resonance condition.

\begin{tabular}{|c|c|c|c|c|c|c|c|c|c|c|c|c|c|c|}
\hline № & $\omega_{1}$ & $m_{1}$ & $n_{1}$ & $\omega_{2}$ & $m_{2}$ & $n_{2}$ & $\omega_{3}$ & $m_{3}$ & $n_{3}$ & $\begin{array}{l}a, \\
\mathrm{~m}\end{array}$ & $\begin{array}{l}b, \\
\mathrm{~m}\end{array}$ & $\begin{array}{c}h, \\
\mathrm{~m}\end{array}$ & $v$ \\
\hline \multicolumn{10}{|c|}{ Combinational resonance: $2 \omega_{3} \simeq \omega_{1}+\omega_{2}$ and force amplitude level $f=10$} \\
\hline 1 & 15.7 & 3 & 1 & 9.29 & 3 & 1 & 13.33 & 6 & 1 & 0.57 & 0.1425 & 0.0513 & 0.3 \\
\hline 2 & 37.83 & 9 & 1 & 44.953 & 3 & 3 & 41.668 & 3 & 3 & 1.14 & 0.1425 & 0.0285 & 0.3 \\
\hline 3 & 16.92 & 5 & 2 & 11.9 & 4 & 5 & 14.25 & 4 & 3 & 0.25 & 0.25 & 0.05 & 0.3 \\
\hline \multicolumn{10}{|c|}{ Combinational resonance: $2 \omega_{3} \simeq \omega_{1}-\omega_{2}$ and force amplitude level $f=10$} \\
\hline 4 & 42.15 & 6 & 3 & 14.985 & 1 & 2 & 13.324 & 6 & 1 & 0.57 & 0.1425 & 0.0513 & 0.3 \\
\hline 5 & 100.58 & 1 & 4 & 14.985 & 1 & 1 & 41.65 & 3 & 3 & 1.14 & 0.1425 & 0.0285 & 0.3 \\
\hline 6 & 32.345 & 9 & 5 & 4.156 & 1 & 2 & 14.245 & 4 & 3 & 0.25 & 0.25 & 0.05 & 0.3 \\
\hline \multicolumn{10}{|c|}{ Combinational resonance: $2 \omega_{3} \simeq \omega_{2}-\omega_{1}$ and force amplitude level $f=1$} & \\
\hline 7 & 26.842 & 3 & 2 & 47.639 & 9 & 6 & 10.51 & 5 & 1 & 0.57 & 0.1425 & 0.0513 & 0.3 \\
\hline 8 & 25.328 & 1 & 1 & 61.783 & 9 & 4 & 18.3 & 1 & 2 & 1.14 & 0.1425 & 0.0285 & 0.3 \\
\hline 9 & 7.025 & 1 & 1 & 13.142 & 5 & 5 & 2.85 & 2 & 1 & 0.25 & 0.25 & 0.05 & 0.3 \\
\hline
\end{tabular}


Analysis of Forced Vibrations of Nonlinear Plates in a Viscoelastic Medium Under the Conditions of the Different Combinational Internal Resonances
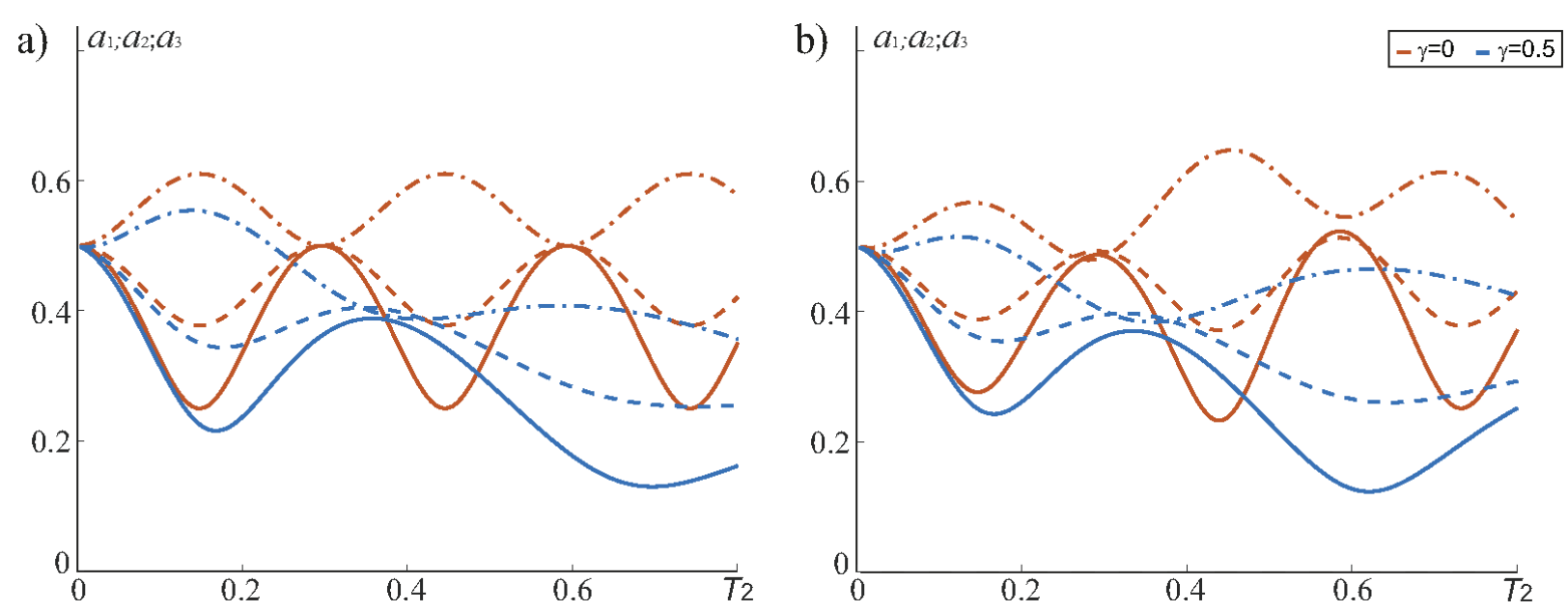

Figure 1. Amplitude envelopes of (a) free and (b) forced vibrations for plate №1 at the initial amplitudes $a_{i 0}=0.5$.
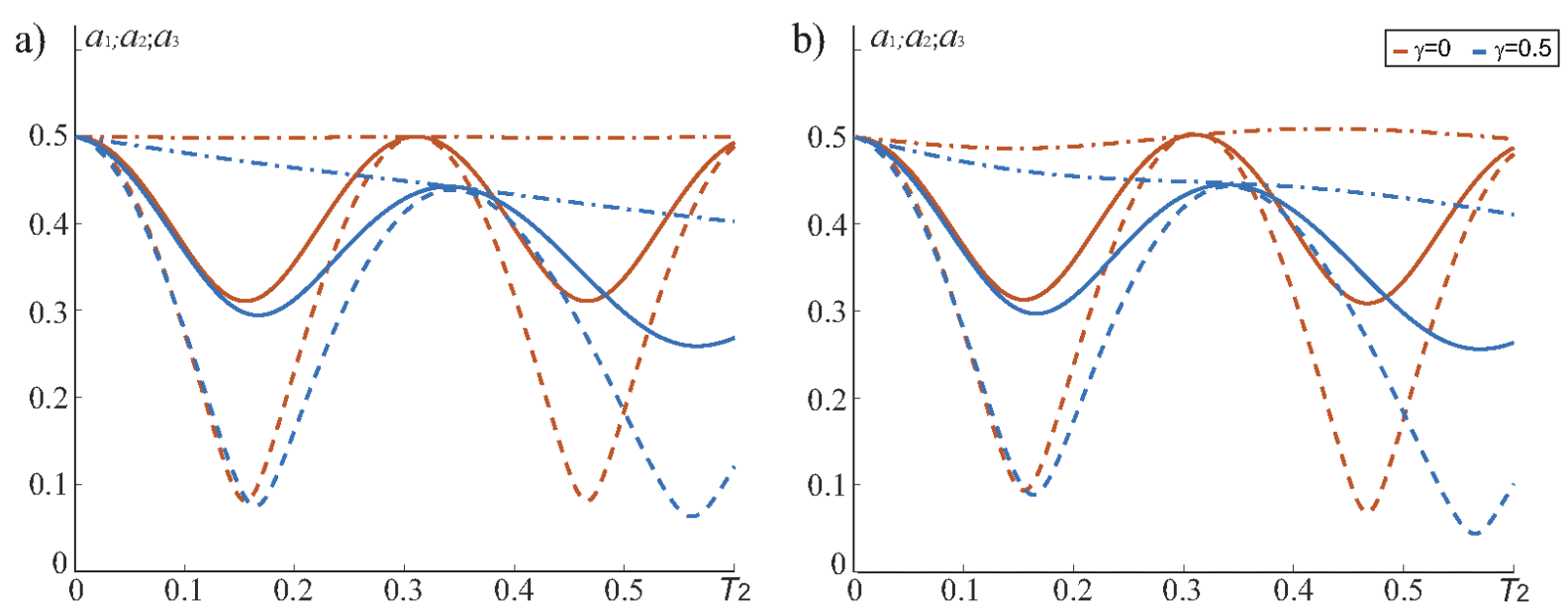

Figure 2. Amplitude envelopes of (a) free and (b) forced vibrations for plate №2 at $a_{i 0}=0.5$.
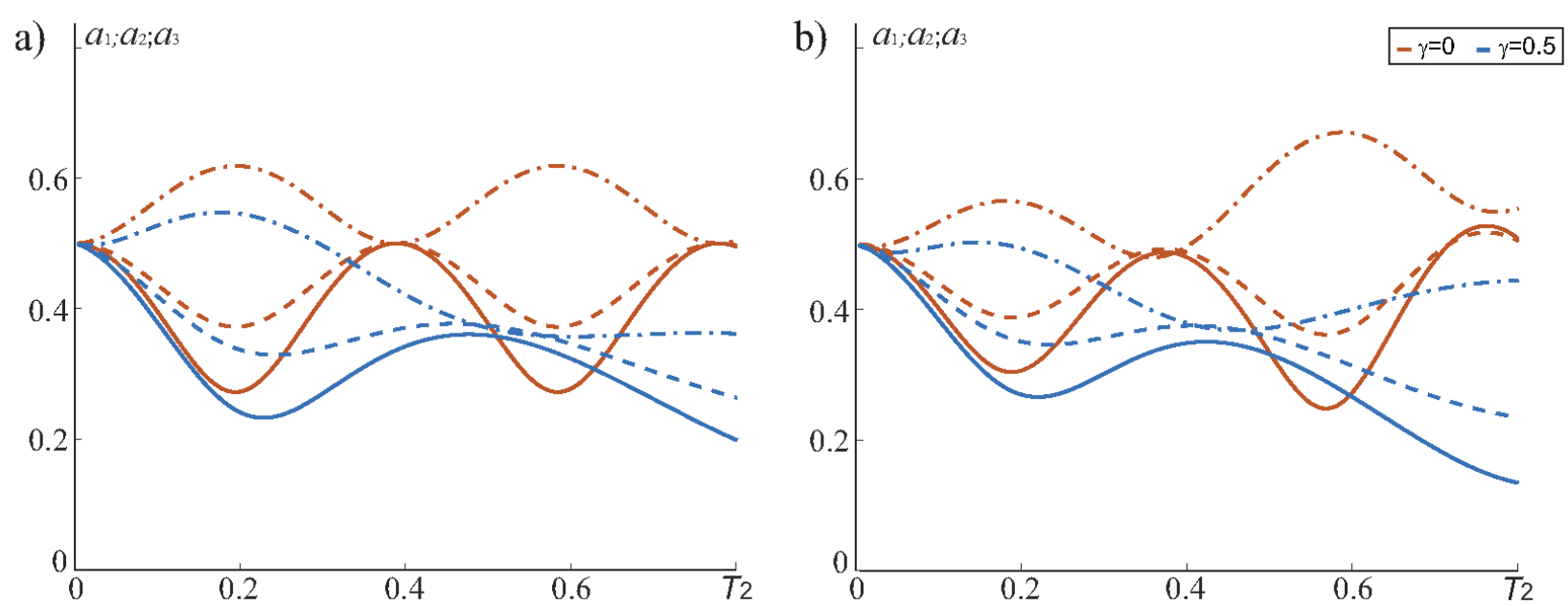

Figure 3. Amplitude envelopes of (a) free and (b) forced vibrations for plate №3 at $a_{i 0}=0.5$. 

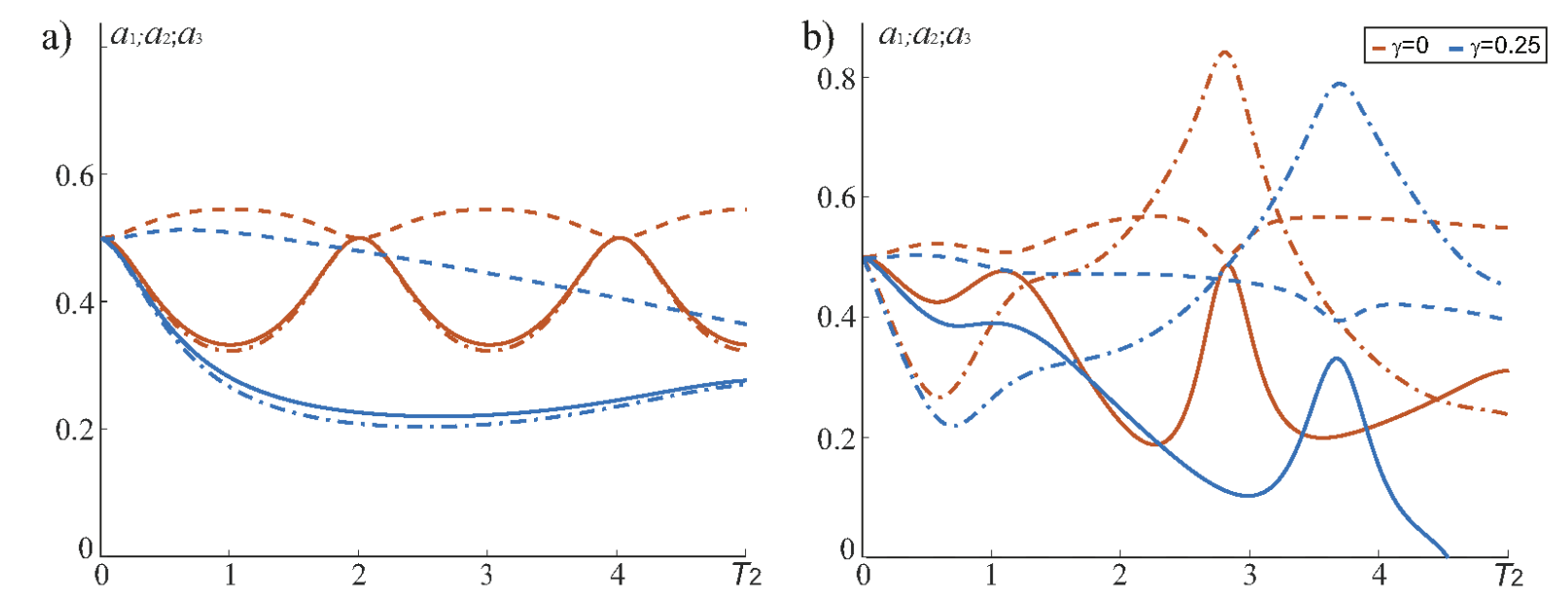

Figure 4. Amplitude envelopes of (a) free and (b) forced vibrations for plate №4 at $a_{i 0}=0.5$.
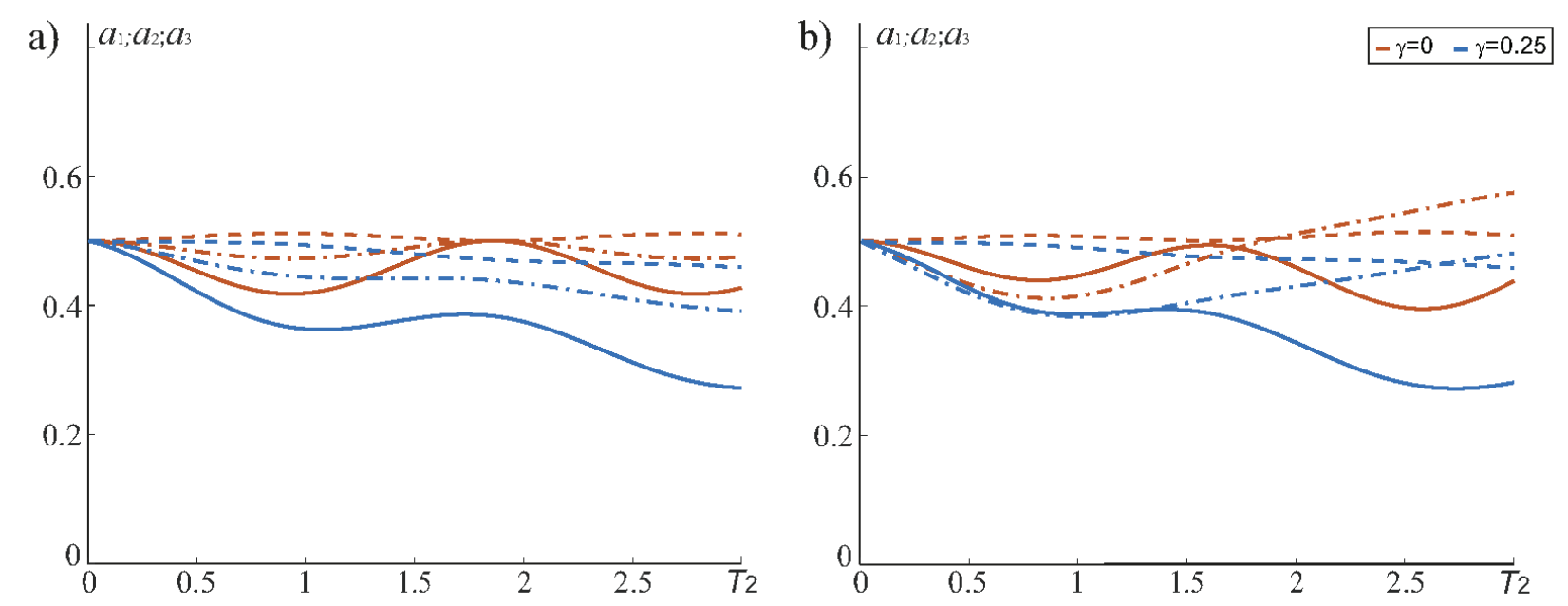

Figure 5. Amplitude envelopes of (a) free and (b) forced vibrations for plate №5 at $a_{i 0}=0.5$.

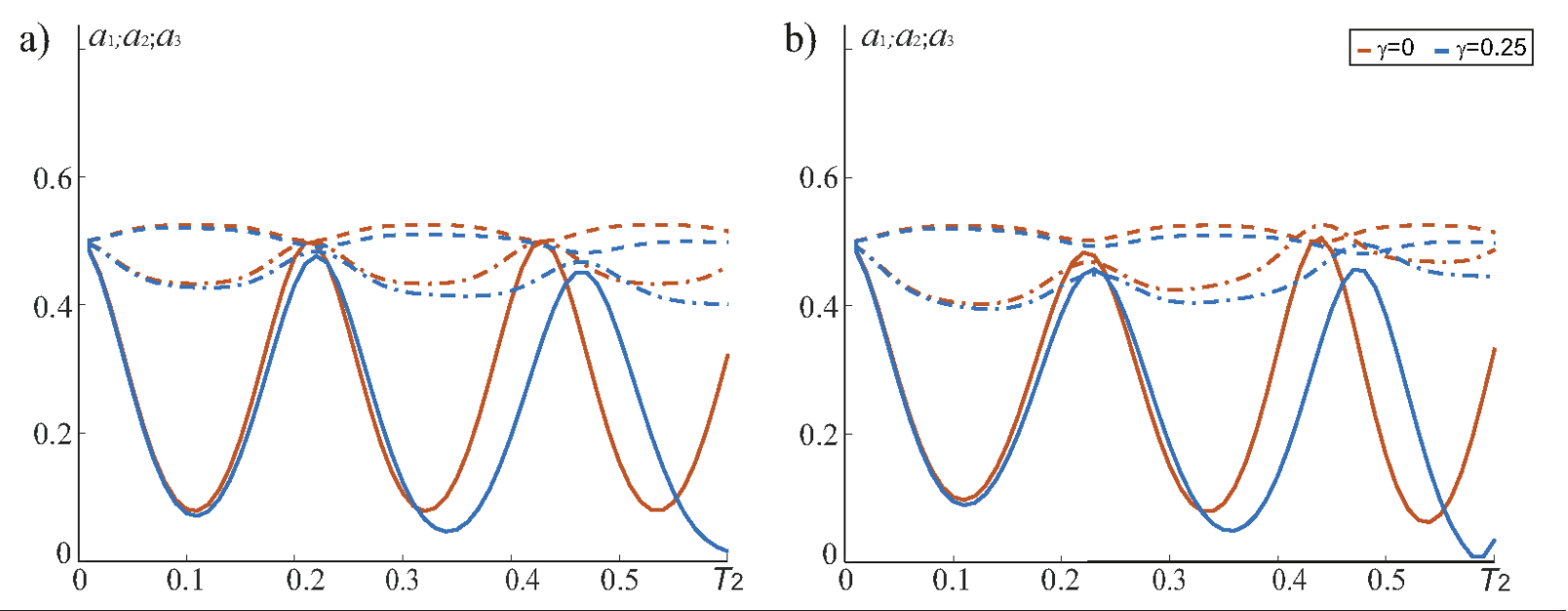

Figure 6. Amplitude envelopes of (a) free and (b) forced vibrations for plate №6 at $a_{i 0}=0.5$. 
Analysis of Forced Vibrations of Nonlinear Plates in a Viscoelastic Medium Under the Conditions of the Different Combinational Internal Resonances
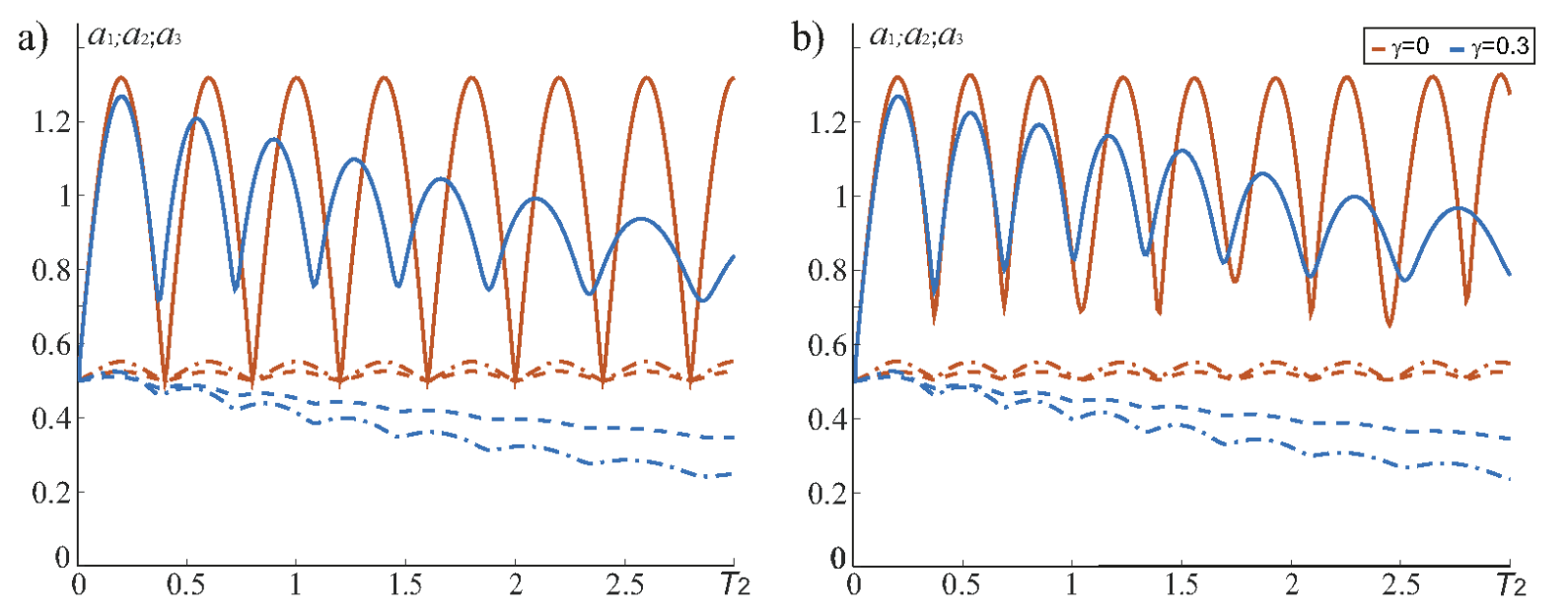

Figure 7. Amplitude envelopes of (a) free and (b) forced vibrations for plate №7 at $a_{i 0}=0.5$.
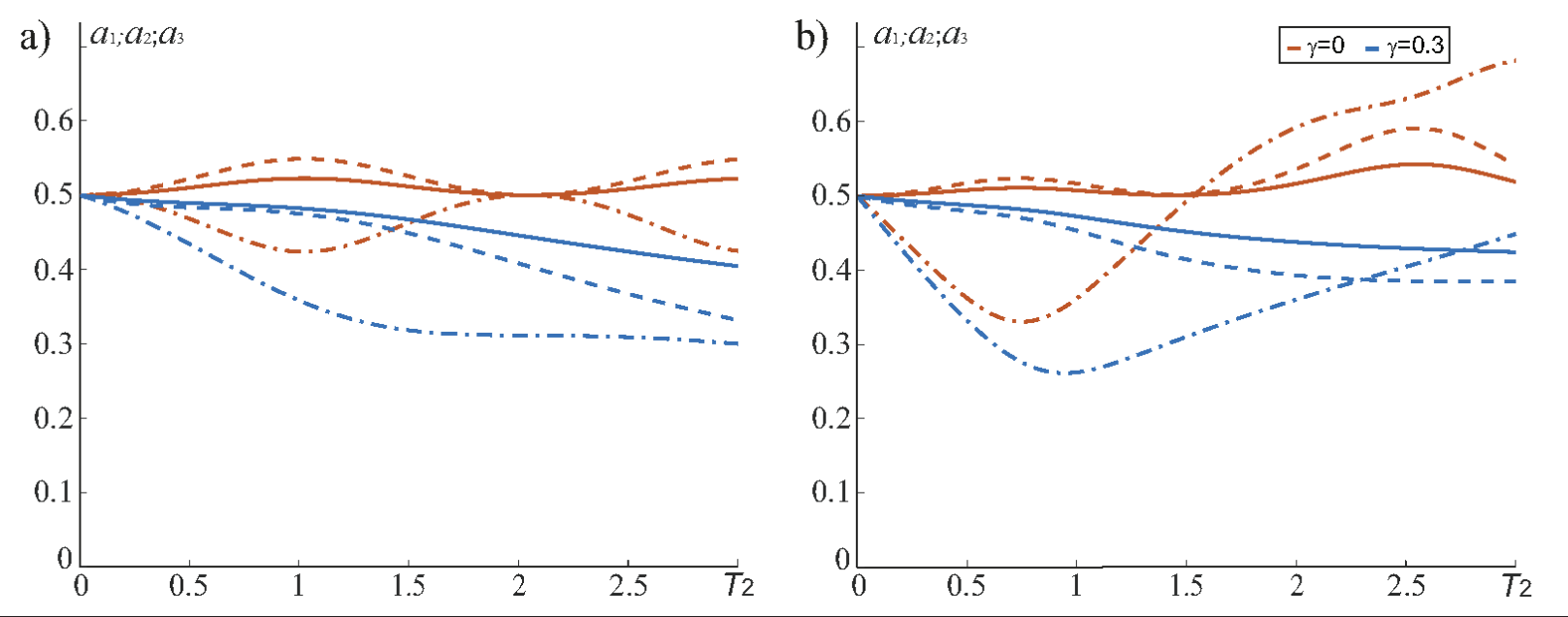

Figure 8. Amplitude envelopes of $(a)$ free and $(b)$ forced vibrations for plate №8 at $a_{i 0}=0.5$.
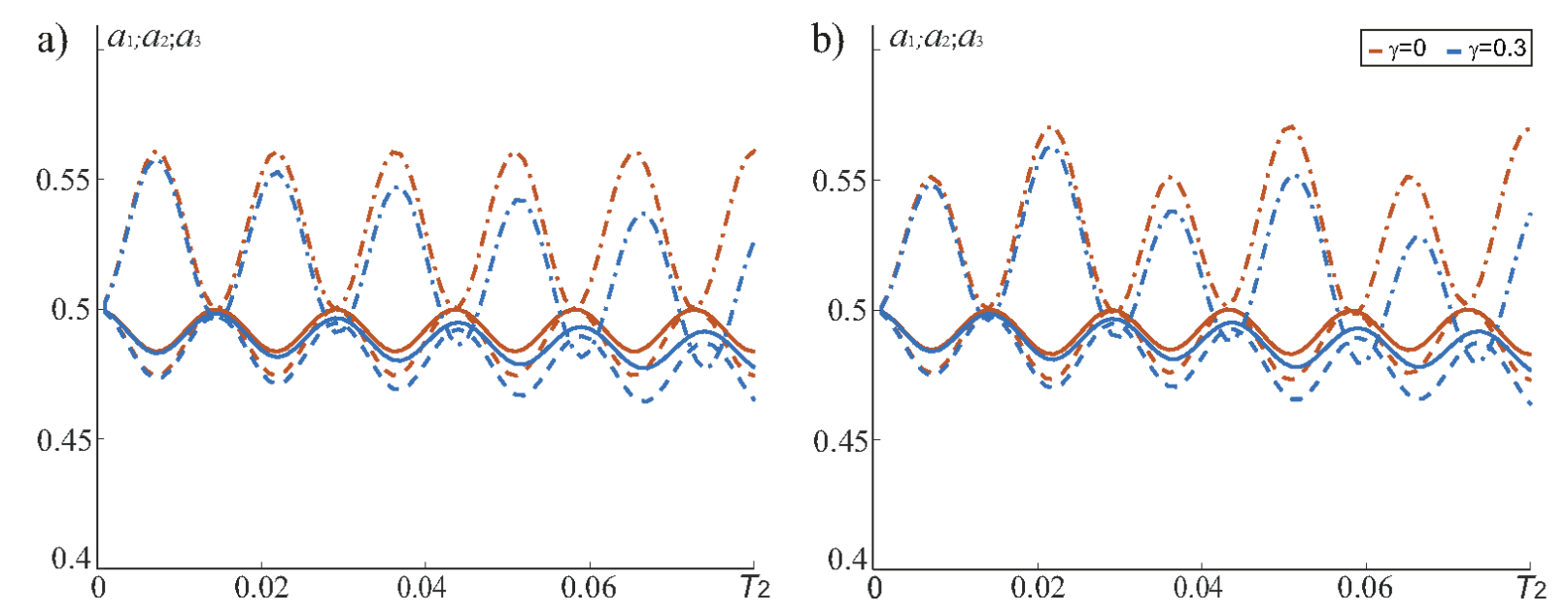

Figure 9. Amplitude envelopes of (a) free and (b) forced vibrations for plate №9 at $a_{i 0}=0.5$. 
since it provides the essential increase in dimensionless amplitudes, resulting in high level of stresses and strains.

The time $T_{2}$-dependence of the amplitude envelopes for an oblong plate with dimensions $a=1.14 \mathrm{~m}$ and $b=0.1425$ (cases 2, 5 and 8 in Table 1) is presented in Figures 2, 5 and 8 at $f=10$, whence it follows that the additive combinational resonance is the most unfavorable, while the difference resonances result in the monotonic variation of dimensionless amplitudes.

As for a square plate (cases 3, 6 and 9 in Table 1 ), then all types of the combinational resonance influence equally on the amplitudes variation with time.

\section{CONCLUSION}

In the present paper, nonlinear force driven vibrations of thin plates in a viscoelastic medium have been studied, when the motion of the plate is described by a set of three coupled nonlinear differential equations subjected to the condition of the combinational resonance accompanied by the external resonance. Nonlinear sets of resolving equations in terms of amplitudes and phase differences have been solved numerically using the Runge-Kutta fourth-order algorithm. The influence of viscosity on the energy exchange mechanism between interacting modes has been analyzed. It has been revealed that plates of different dimensions behave in a different manner under the additive and difference combinational resonances. Rectangular plates are more sensitive to plate's dimensions than square ones.

\section{FUNDING}

This research has been supported by the Ministry of Education and Science of the Russian Federation (Project 9.5138.2017/8.9).

\section{REFERENCES}

1. Amabili M. Nonlinear vibrations of rectangular plates with different boundary conditions: theory and experiments. // Computers \& Structures, 2004, 82, pp. 2587-2605.

2. Amabili M. Nonlinear Vibrations and Stability of Shells and Plates. Cambridge University Press, London, 2008, 391 pages.

3. Breslavsky I.D., Amabili M., Legrand M. Physically and geometrically non-linear vibrations of thin rectangular plates. // International Journal of Non-Linear Mechanics, 2014, Vol. 58, pp. 30-40.

4. Amabili M. Nonlinear vibrations of viscoelastic rectangular plates. // Journal of Sound and Vibration, 2016, Vol. 362, pp. 142-156.

5. Amabili M. Nonlinear damping in nonlinear vibrations of rectangular plates: Derivation from viscoelasticity and experimental validation. // Journal of the Mechanics and Physics of Solids, 2018, Vol. 118, pp. 275-292.

6. Amabili M. Nonlinear damping in largeamplitude vibrations: modelling and experiments. // Nonlinear Dynamics, 2018, Vol. 93(1), pp. 5-18.

7. Rossikhin Yu. A., Shitikova M.V. Thin bodies embedded in fractional derivative viscoelastic medium. // Dynamic response, In: Encyclopedia of Continuum Mechanics, edited by H. Altenbach, A. Ochsner, Springer, Berlin, Heidelberg, 2019.

8. Clough R.W., Penzien J. Dynamics of Structures. McGraw-Hill, New York, 1975.

9. Hedrih K.R., Simonovic J.D. Structural analogies on systems of deformable bodies coupled with non-linear layers. // International Journal of Non-Linear Mechanics, 2015, Vol. 73, pp. 18-24.

10. Ribeiro P., Petyt M. Nonlinear free vibration of isotropic plates with internal resonance // International Journal of NonLinear Mechanics, 2000, Vol. 35, pp. 263278. 
Analysis of Forced Vibrations of Nonlinear Plates in a Viscoelastic Medium Under the Conditions of the Different

Combinational Internal Resonances

11. Nayfeh A.H. Nonlinear interaction: Analytical, computational, and experimental methods. New York, Wiley, 2000.

12. Chang S.I., Bajaj A.K., Krousgrill C.M. Non-linear vibrations and chaos in harmonically excited rectangular plates with one-to-one internal resonance. // Nonlinear Dynamics, 1993, Vol. 4(5), pp 433-460.

13. Anlas G., Elbeyli O. Nonlinear vibrations of a simply supported rectangular metallic plate subjected to transverse harmonic excitation in the presence of a one-to-one internal resonance. // Nonlinear Dynamics, 2002, Vol. 30(1), pp. 1-28.

14. Hao Y.X., Zhang W., Ji X.L. Nonlinear dynamic response of functionally graded rectangular plates under different internal resonances. // Mathematical Problems in Engineering, 2010, Vol. 33, Article ID 738648.

15. Rossikhin Yu.A., Shitikova M.V. Free damped non-linear vibrations of a viscoelastic plate under the two-to-one internal resonance. // Materials Science Forum, 2003, Vols. 440-441, pp. 29-36.

16. Rossikhin Yu.A.2 Shitikova M.V., Ovsjannikova E.I. Free damped vibrations of a nonlinear rectangular thin plate under the conditions of internal combinational resonance. // Nonlinear Acoustics at the Beginning of the 21st Century, Proceedings of the 16th International Symposium on Nonlinear Acoustics (O.V. Rudenko and O.A. Sapozhnikov, eds.), August 19-23, 2002, Moscow, Russia, Vol. 2, pp. 693-696.

17. Rossikhin Yu.A., Shitikova M.V. Analysis of free non-linear vibrations of a viscoelastic plate under the conditions of different internal resonances. // International Journal of Non-Linear Mechanics, 2006, Vol. 2, pp. 313-325.

18. Rossikhin Yu.A., Shitikova M.V., Ngenzi J.Cl. A new approach for studying nonlinear dynamic response of a thin plate with internal resonance in a fractional viscoelastic medium. // Shock and Vibration, 2015, Article ID 795606.

19. Rossikhin Yu.A., Shitikova M.V., Ngenzi J.Cl. Phenomenological analysis of the additive combinational internal resonance in nonlinear vibrations of fractionally damped thin plates. // WSEAS Transactions on Applied and Theoretical Mechanics, 2015, Vol. 10, pp. 260-276.

20. Rossikhin Yu.A., Shitikova M.V., Ngenzi J.Cl. Fractional calculus application in problems of non-linear vibrations of thin plates with combinational internal resonances. // Procedia Engineering, 2016, Vol. 144, pp. 849-858.

21. Witt A.A., Gorelik G.S. Oscillations of an elastic pendulum as an example of the oscillations of two parametrically coupled linear systems. // Journal Technical Physics, 1933, Vol. 3(2-3), pp. 294-307.

22. Rossikhin Yu.A., Shitikova M.V. Applications of fractional calculus to dynamic problems of linear and nonlinear hereditary mechanics of solids. // Applied Mechanics Reviews, 1997, Vol. 50, pp. 1567.

23. Abdel-Ghaffar A.M., Housner G.W. Ambient vibration tests of suspension bridge. // Journal of the Engineering Mechanics Division, 1978, Vol. 104(5), pp. 983-999.

24. Abdel-Ghaffar A.M., Scanlan R.H. Ambient vibration studies of Golden Gate bridge: I. Suspended structure. // ASCE Journal of Engineering Mechanics, 1985, Vol. 111, pp. 463-482.

25. Rossikhin Yu.A., Shitikova M.V. Application of fractional calculus for analysis of nonlinear damped vibrations of suspension bridges. // Journal of Engineering Mechanics, 1998, Vol. 124, pp. 1029-1036.

26. Rossikhin Yu.A., Shitikova M.V. Application of fractional calculus for dynamic problems of solid mechanics: novel trends and recent results. // Applied 
Mechanics Reviews, 2010, Vol. 63, Article ID 01081.

27. Rossikhin Yu.A., Shitikova M.V. Fractional calculus in structural mechanics, In: Handbook of Fractional Calculus with Applications. Vol 7: Applications in Engineering, Life and Social Sciences, Part A, edited by D. Baleanu, A.M. Lopes (De Gruyter, Berlin, 2019), pp. 159-192.

28. (Stevanovic) Hedrih K. Partial fractional differential equations of creeping and vibrations of plate and their solutions (First part). // Journal of Mechanical Behavior of Materials, 2005, Vol. 16, Issue 4-5, pp. 305-314.

29. Ingman D., Suzdalnitsky J. Response of viscoelastic plate to impact. // ASME Journal of Vibration and Acoustics, 2008, Vol. 131(7), pp. 763-767.

30. Rossikhin Yu.A., Shitikova M.V. Analysis of damped vibrations of linear viscoelastic plates with damping modeled with fractional derivatives. // Signal Processing, 2006, Vol. 86(10), pp. 2703-2711.

31. (Stevanovic) Hedrih K. Dynamics of coupled systems. // Nonlinear Analysis: Hybrid Systems, 2008, Vol. 2, pp. 310-334.

32. Rossikhin Yu.A., Shitikova M.V., Trung P.T. Application of the fractional derivative Kelvin-Voigt model for the analysis of impact response of a Kirchhoff-Love plate. // WSEAS Transactions on Mathematics, 2016, Vol. 15, pp. 498-501.

33. Hilton H.H. Implications and constraints of time-independent Poisson ratios in linear isotropic and anisotropic viscoelasticity. // Journal of Elasticity, 2001, Vol. 63(3), pp. 221-251.

34. Ari M., Faal R.T., Zayernouri M. Vibrations suppression of fractionally damped plates using multiple optimal dynamic vibration. // International Journal of Computer Mathematics, 2019, DOI: 10.1080/00207160.2019.1594792.

35. Mashrouteh S. Nonlinear vibration analysis of viscoelastic plates with fractional damping. Master Thesis,
University of Ontario, Institute of Technology, 2017.

36. Permoon M. R., Haddadpour H., Javadi M. Nonlinear vibration of fractional viscoelastic plate: primary, subharmonic, and superharmonic response. // International Journal of Non-Linear Mechanics, 2018, Vol. 99, pp. 154-164.

37. Babouskos N.G., Katsikadelis J.T. Nonlinear vibrations of viscoelastic plates of fractional derivative type: An AEM solution. // The Open Mechanics Journal, 2010, Vol. 4(8), pp. 8-20.

38. Hosseinkhani A., Younesian D., Farhangdoust S. Dynamic analysis of a plate on the generalized foundation with fractional damping subjected to random excitation. // Mathematical Problems in Engineering, 2018, ID 3908371.

39. Malara G., Spanos P.D. Nonlinear random vibrations of plates endowed with fractional derivative elements. // Probabilistic Engineering Mechanics, 2018, Vol. 54, pp. 2-8.

40. Nwagoum Tuwa P.R., Miwadinou C.H., Monwanou A.V., Chabi Orou J.B., Woafo P. Chaotic vibrations of nonlinear viscoelastic plate with fractional derivative model and subjected to parametric and external excitations. // Mechanics Research Communications, 2019, Vol. 97, pp. 8-15.

41. Litewka P., Lewandowski R. Steady-state non-linear vibrations of plates using Zener material model with fractional derivative. // Computational Mechanics, 2017, Vol. 60, pp. 333-354.

42. Datta P., Ray M.C. Fractional order derivative model of viscoelastic layer for active damping of geometrically nonlinear vibrations of smart composite plates. // CMC, 2015, Vol. 49-50(1), pp. 47-80.

43. Rossikhin Yu.A., Shitikova M.V., Shcheglova T.A. Forced vibrations of a nonlinear oscillator with weak fractional damping. // Journal of Mechanics of Materials and Structures, 2009, Vol. 4(9), pp. 1619-1636. 
Analysis of Forced Vibrations of Nonlinear Plates in a Viscoelastic Medium Under the Conditions of the Different

Combinational Internal Resonances

44. Shitikova M.V., Rossikhin Yu.A., Kandu V. Interaction of internal and external resonances during force driven vibrations of a nonlinear thin plate embedded into a fractional derivative medium. // Procedia Engineering, 2017, Vol. 199, pp. 832-837.

45. Shitikova M.V., Kandu V.V. Chislennyj analiz vynuzhdennyh kolebanij nelinejnyh plastinok v vjazkouprugoj srede pri nalichii vnutrennego rezonansa odin $\mathrm{k}$ odnomu [Force driven nonlinear vibrations of a thin plate in one-to-one internal resonance in a fractional viscoelastic medium]. // News of higher educational institutions. Construction, 2018, 12, pp. 9-22.

46. Samko S.G., Kilbas A.A., Marichev O.I. fractional integrals and derivatives. theory and applications. Gordon and Breach Science Publishers, Amsterdam, 1993.

47. Kandu V.V., Shitikova M.V., Rossikhin Yu.A. Chislennyj analiz vynuzhdennyh kolebanij nelinejnyh plastinok v vjazkouprugoj srede pri nalichii vnutrennego rezonansa 1:1:2 [Numerical analysis of forced nonlinear vibrations of plates in a viscoelastic medium at the presence of the 1:1:2 internal resonance]. // Proceedings of the $X$ All-Russian Conference on Mechanics of Deformable Solids, Samara, 18-22 September 2017, Vol. 2, pp. 10-12.

48. Shitikova M.V., Kandu V.V. Modelirovanie vynuzhdennyh kolebanij nelinejnyh plastinok v vjazkouprugoj srede pri nalichii vnutrennego rezonansa 1:1:1 [Modelling of forced vibrations of nonlinear plates in a viscoelastic medium at the 1:1:1 internal resonance]. // Proceedings of the International Conference on Actual Problems of Applied Mathematics, Informatics, and Mechanics, Voronezh, 1719 December, 2018. Voronezh, Publishing House "Research Publications", 2019, pp. 1295-1300.

\section{СПИСОК ЛИТЕРАТУРЫ}

1. Amabili M. Nonlinear vibrations of rectangular plates with different boundary conditions: theory and experiments. // Computers \& Structures, 2004, 82, pp. 2587-2605.

2. Amabili M. Nonlinear Vibrations and Stability of Shells and Plates. Cambridge University Press, London, 2008, 391 pages.

3. Breslavsky I.D., Amabili M., Legrand M. Physically and geometrically non-linear vibrations of thin rectangular plates. // International Journal of Non-Linear Mechanics, 2014, Vol. 58, pp. 30-40.

4. Amabili M. Nonlinear vibrations of viscoelastic rectangular plates. // Journal of Sound and Vibration, 2016, Vol. 362, pp. 142-156.

5. Amabili M. Nonlinear damping in nonlinear vibrations of rectangular plates: Derivation from viscoelasticity and experimental validation. // Journal of the Mechanics and Physics of Solids, 2018, Vol. 118, pp. 275-292.

6. Amabili M. Nonlinear damping in largeamplitude vibrations: modelling and experiments. // Nonlinear Dynamics, 2018, Vol. 93(1), pp. 5-18.

7. Rossikhin Yu. A., Shitikova M.V. Thin bodies embedded in fractional derivative viscoelastic medium. // Dynamic response, In: Encyclopedia of Continuum Mechanics, edited by $\mathrm{H}$. Altenbach, A. Ochsner, Springer, Berlin, Heidelberg, 2019.

8. Clough R.W., Penzien J. Dynamics of Structures. McGraw-Hill, New York, 1975.

9. Hedrih K.R., Simonovic J.D. Structural analogies on systems of deformable bodies coupled with non-linear layers. // International Journal of Non-Linear Mechanics, 2015, Vol. 73, pp. 18-24.

10. Ribeiro P., Petyt M. Nonlinear free vibration of isotropic plates with internal resonance // International Journal of NonLinear Mechanics, 2000, Vol. 35, pp. 263278. 
11. Nayfeh A.H. Nonlinear interaction: Analytical, computational, and experimental methods. New York, Wiley, 2000.

12. Chang S.I., Bajaj A.K., Krousgrill C.M. Non-linear vibrations and chaos in harmonically excited rectangular plates with one-to-one internal resonance. // Nonlinear Dynamics, 1993, Vol. 4(5), pp 433-460.

13. Anlas G., Elbeyli O. Nonlinear vibrations of a simply supported rectangular metallic plate subjected to transverse harmonic excitation in the presence of a one-to-one internal resonance. // Nonlinear Dynamics, 2002, Vol. 30(1), pp. 1-28.

14. Hao Y.X., Zhang W., Ji X.L. Nonlinear dynamic response of functionally graded rectangular plates under different internal resonances. // Mathematical Problems in Engineering, 2010, Vol. 33, Article ID 738648.

15. Rossikhin Yu.A., Shitikova M.V. Free damped non-linear vibrations of a viscoelastic plate under the two-to-one internal resonance. // Materials Science Forum, 2003, Vols. 440-441, pp. 29-36.

16. Rossikhin Yu.A.2 Shitikova M.V., Ovsjannikova E.I. Free damped vibrations of a nonlinear rectangular thin plate under the conditions of internal combinational resonance. // Nonlinear Acoustics at the Beginning of the 21st Century, Proceedings of the 16th International Symposium on Nonlinear Acoustics (O.V. Rudenko and O.A. Sapozhnikov, eds.), August 19-23, 2002, Moscow, Russia, Vol. 2, pp. 693-696.

17. Rossikhin Yu.A., Shitikova M.V. Analysis of free non-linear vibrations of a viscoelastic plate under the conditions of different internal resonances. // International Journal of Non-Linear Mechanics, 2006, Vol. 2, pp. 313-325.

18. Rossikhin Yu.A., Shitikova M.V., Ngenzi J.Cl. A new approach for studying nonlinear dynamic response of a thin plate with internal resonance in a fractional viscoelastic medium. // Shock and Vibration, 2015, Article ID 795606.

19. Rossikhin Yu.A., Shitikova M.V., Ngenzi J.Cl. Phenomenological analysis of the additive combinational internal resonance in nonlinear vibrations of fractionally damped thin plates. // WSEAS Transactions on Applied and Theoretical Mechanics, 2015, Vol. 10, pp. 260-276.

20. Rossikhin Yu.A., Shitikova M.V., Ngenzi J.Cl. Fractional calculus application in problems of non-linear vibrations of thin plates with combinational internal resonances. // Procedia Engineering, 2016, Vol. 144, pp. 849-858.

21. Witt A.A., Gorelik G.S. Oscillations of an elastic pendulum as an example of the oscillations of two parametrically coupled linear systems. // Journal Technical Physics, 1933, Vol. 3(2-3), pp. 294-307.

22. Rossikhin Yu.A., Shitikova M.V. Applications of fractional calculus to dynamic problems of linear and nonlinear hereditary mechanics of solids. // Applied Mechanics Reviews, 1997, Vol. 50, pp. 1567.

23. Abdel-Ghaffar A.M., Housner G.W. Ambient vibration tests of suspension bridge. // Journal of the Engineering Mechanics Division, 1978, Vol. 104(5), pp. 983-999.

24. Abdel-Ghaffar A.M., Scanlan R.H. Ambient vibration studies of Golden Gate bridge: I. Suspended structure. // ASCE Journal of Engineering Mechanics, 1985, Vol. 111, pp. 463-482.

25. Rossikhin Yu.A., Shitikova M.V. Application of fractional calculus for analysis of nonlinear damped vibrations of suspension bridges. // Journal of Engineering Mechanics, 1998, Vol. 124, pp. 1029-1036.

26. Rossikhin Yu.A., Shitikova M.V. Application of fractional calculus for dynamic problems of solid mechanics: novel trends and recent results. // Applied 
Analysis of Forced Vibrations of Nonlinear Plates in a Viscoelastic Medium Under the Conditions of the Different Combinational Internal Resonances

Mechanics Reviews, 2010, Vol. 63, Article ID 01081.

27. Rossikhin Yu.A., Shitikova M.V. Fractional calculus in structural mechanics, In: Handbook of Fractional Calculus with Applications. Vol 7: Applications in Engineering, Life and Social Sciences, Part A, edited by D. Baleanu, A.M. Lopes (De Gruyter, Berlin, 2019), pp. 159-192.

28. (Stevanovic) Hedrih K. Partial fractional differential equations of creeping and vibrations of plate and their solutions (First part). // Journal of Mechanical Behavior of Materials, 2005, Vol. 16, Issue 4-5, pp. 305-314.

29. Ingman D., Suzdalnitsky J. Response of viscoelastic plate to impact. // ASME Journal of Vibration and Acoustics, 2008, Vol. 131(7), pp. 763-767.

30. Rossikhin Yu.A., Shitikova M.V. Analysis of damped vibrations of linear viscoelastic plates with damping modeled with fractional derivatives. // Signal Processing, 2006, Vol. 86(10), pp. 2703-2711.

31. (Stevanovic) Hedrih K. Dynamics of coupled systems. // Nonlinear Analysis: Hybrid Systems, 2008, Vol. 2, pp. 310-334.

32. Rossikhin Yu.A., Shitikova M.V., Trung P.T. Application of the fractional derivative Kelvin-Voigt model for the analysis of impact response of a Kirchhoff-Love plate. // WSEAS Transactions on Mathematics, 2016, Vol. 15, pp. 498-501.

33. Hilton H.H. Implications and constraints of time-independent Poisson ratios in linear isotropic and anisotropic viscoelasticity. // Journal of Elasticity, 2001, Vol. 63(3), pp. 221-251.

34. Ari M., Faal R.T., Zayernouri M. Vibrations suppression of fractionally damped plates using multiple optimal dynamic vibration. // International Journal of Computer Mathematics, 2019, DOI: 10.1080/00207160.2019.1594792.

35. Mashrouteh S. Nonlinear vibration analysis of viscoelastic plates with fractional damping. Master Thesis,
University of Ontario, Institute of Technology, 2017.

36. Permoon M. R., Haddadpour H., Javadi M. Nonlinear vibration of fractional viscoelastic plate: primary, subharmonic, and superharmonic response. // International Journal of Non-Linear Mechanics, 2018, Vol. 99, pp. 154-164.

37. Babouskos N.G., Katsikadelis J.T. Nonlinear vibrations of viscoelastic plates of fractional derivative type: An AEM solution. // The Open Mechanics Journal, 2010, Vol. 4(8), pp. 8-20.

38. Hosseinkhani A., Younesian D., Farhangdoust S. Dynamic analysis of a plate on the generalized foundation with fractional damping subjected to random excitation. // Mathematical Problems in Engineering, 2018, ID 3908371.

39. Malara G., Spanos P.D. Nonlinear random vibrations of plates endowed with fractional derivative elements. // Probabilistic Engineering Mechanics, 2018, Vol. 54, pp. 2-8.

40. Nwagoum Tuwa P.R., Miwadinou C.H., Monwanou A.V., Chabi Orou J.B., Woafo P. Chaotic vibrations of nonlinear viscoelastic plate with fractional derivative model and subjected to parametric and external excitations. // Mechanics Research Communications, 2019, Vol. 97, pp. 8-15.

41. Litewka P., Lewandowski R. Steady-state non-linear vibrations of plates using Zener material model with fractional derivative. // Computational Mechanics, 2017, Vol. 60, pp. 333-354.

42. Datta P., Ray M.C. Fractional order derivative model of viscoelastic layer for active damping of geometrically nonlinear vibrations of smart composite plates. // CMC, 2015, Vol. 49-50(1), pp. 47-80.

43. Rossikhin Yu.A., Shitikova M.V., Shcheglova T.A. Forced vibrations of a nonlinear oscillator with weak fractional damping. // Journal of Mechanics of Materials and Structures, 2009, Vol. 4(9), pp. 1619-1636. 
44. Shitikova M.V., Rossikhin Yu.A., Kandu V. Interaction of internal and external resonances during force driven vibrations of a nonlinear thin plate embedded into a fractional derivative medium. // Procedia Engineering, 2017, Vol. 199, pp. 832-837.

45. Шитикова М.В., Канду В.В. Численный анализ вынужденных колебаний нелинейных пластинок в вязкоупругой среде при наличии внутреннего резонанса один к одному. // Известия высших учебных заведений. Строительство, 2018, №12(720), с. 9-22.

46. Samko S.G., Kilbas A.A., Marichev O.I. fractional integrals and derivatives. theory and applications. Gordon and Breach Science Publishers, Amsterdam, 1993.

47. Канду В.В., Шитикова М.В., Россихин Ю.А. Численный анализ вынужденных колебаний нелинейных пластинок в вязкоупругой среде при наличии внутреннего резонанса 1:1:2. // Сборник материалов всероссийской конференции по механике деформируемого твердого тела, 2017, с. 10-12.

48. Шитикова М.В., Канду В.В. Моделирование вынужденных колебаний нелинейных пластинок в вязкоупругой среде при наличии внутреннего резонанса 1:1:1. // Сборник трудов Международной научной конференции «Актуальные проблемы прикладной математики, информатики и механики», 2018, с. 1295-1300.

Marina V. Shitikova, Advisor of the Russian Academy of Architecture and Construction Sciences, Prof., Dr.Sc., Research Center on Dynamics of Solids and Structures; Voronezh State Technical University; 20-letiya Oktyabrya 84, Voronezh, 394006, Russia; phone +7 (473) 271-42-20; fax +7 (473) 277-39-92;

E-mail: mvs@vgasu.vrn.ru.

Vladimir V. Kandu, Ph.D. student; Junior Researcher; Research Center on Dynamics of Solids and Structures; Voronezh State Technical University; 20-letiya Oktyabrya 84, Voronezh, 394006, Russia;

phone +7 (473) 271-42-20; fax +7 (473) 277-39-92;

E-mail: kandu8vladimir@gmail.com.
Шитикова Марина Вячеславовна, советник РААСН, профессор, доктор физико-математических наук; руководитель международного научного центра по фундаментальным исследованиям в области естественных и строительных наук имени Заслуженного деятеля науки РФ, профессора Россихина Ю.А.; Воронежский государственный технический университет; 394006, Россия, г. Воронеж, ул. 20 лет Октября, д. 84;

E-mail: mvs@vgasu.vrn.ru

Владимир В. Канду аспирант, младший научный сотрудник международного научного центра по фундаментальным исследованиям в области естественных и строительных наук имени Заслуженного деятеля науки РФ, профессора Россихина Ю.А.; Воронежский государственный технический университет; 394006, Россия, г. Воронеж, ул. 20 лет Октября, д. 84;

E-mail: kandu8vladimir@gmail.com 